\title{
THE MEIXNER PROCESS FOR FINANCIAL DATA
}

The most famous Black-Scholes model is based on the assumption that the log-returns of financial data follow a normal distribution. Several studies performed show empirical evidence against such normality since the log-returns of most financial data show a significant leptokurtosis. The Meixner distribution is an infinitely divisible distribution and therefore a Lévy process can be associated with it, which is called the Meixner process. The Meixner process because of its simple and extreme flexible structure was proposed as a model for representing efficiently the empirical distributions of the log-returns of financial data. In this paper we studied the dynamics of the USD/EUR exchange rates. After testing that the normal distribution provides a poor fit to the log-returns of the exchange rates, we applied the Meixner model fitting its underlying distribution to the data. Performing a number of statistical tests we showed that the Meixner distribution provides an almost perfect fit to the data.

Key words: Lévy stochastic process, Meixner distribution, USD/EUR rates

\section{Introduction}

The Meixner process, introduced by Schoutens and Teugels ${ }^{1}$, assumes great importance in the study of financial data dynamics (Grigelionis, 1999²; Grigelionis, 2001 ${ }^{3}$; Mazzola and Muliere, 2011 ${ }^{4}$ ) because of its intrinsic properties which allow a strictly stochastic interpretation to the results, and of its extreme flexibility as well, which enables to represent efficiently the empirical distributions of many financial data.

Recently the analysis of financial data showed interest on the dynamics of exchange rates. In this paper we analyze the USD/EUR exchange rates and determine if changes in such rates can be represented by a Meixner distribution.

Adjunct Professor Antonella Nannavecchia, PhD, Faculty of Economics, University LUM Jean Monnet, Casamassima, Bari, Italy, e-mail: nannavecchia@lum.it

1 Schoutens, W., Teugels, J. L. (1998): "Lévy processes, polynomials and martingales", Stochastic Models, 14(1-2), 335-349.

2 Grigelionis, B. (1999): "Processes of Meixner Type", Lithuanian Mathematical Journal, 39(1), 33-41.

3 Grigelionis, B. (2001): "Generalized Z-distributions and related stochastic processes", Lithuanian Mathematical Journal, 41(3), 239-251.

$4 \quad$ Mazzola, E., Muliere, P. (2011): "Reviewing alternative characterizations of Meixner process”, Probability Surveys, 8, 127-154. 
In Section 2 we present the analytical expression of the main properties of the Meixner process. In Section 3 we show the empirical features of the logreturns of USD/EUR exchange rates and fit the Meixner distribution. Moreover, we prove the fitting accuracy through some statistical tests. Section 4 presents discussions and conclusions.

\section{The Meixner distribution}

The probability density function (pdf) of the Meixner distribution is given by $f(x)=\frac{\left[2 \cos \left(\frac{b}{2}\right)\right]^{2 d}}{2 a \pi \Gamma(2 d)} \exp \left[\frac{b(x-m)}{a}\right]\left|\Gamma\left[d+\frac{i(x-m)}{a}\right]\right|^{2}, \quad-\infty<x<+\infty$,

$-\infty<m<+\infty, a>0,-\pi<x<+\pi, d>0$. The analytic expression of the cumulative distribution function (cdf) of the Meixner distribution is unknown but it can be computed numerically. The four parameters characterizing the Meixner distribution make it very flexible, allowing a good fitting of the empirical distributions of the log-returns of financial data (Schoutens, $2001^{5}$; Schoutens, $2002^{6}$; Schoutens, 2003 ; Grigoletto and Provasi, $2009^{8}$ ).

The cumulant-generating function of the Meixner distribution is

$$
K(u)=2 d \log \left[\cos \left(\frac{b}{2}\right)\right]-2 d \log \left[\cosh \left(\frac{a u-i b}{2}\right)\right]+i m .
$$

The previous function allows to obtain the expressions of the moments and, therefore, the expressions of the following statistical indicators:

mean

$$
\mu=E(X)=m+a d \tan \left(\frac{b}{2}\right)
$$

variance

$$
\sigma^{2}=\operatorname{Var}(X)=\frac{a^{2} d}{2\left[\cos \left(\frac{b}{2}\right)\right]^{2}}
$$

5 Schoutens, W. (2001): "Meixner process in Finance”, Eurandom Report 2001-002, Eindhoven, 1-21.

6 Schoutens, W. (2002): "The Meixner process: Theory and applications in Finance", Eurandom Report 2001-004, Eindhoven, 1-24.

7 Schoutens, W. (2003): Lévy Processes in Finance, New York: John Wiley \& Sons.

8 Grigoletto, M., Provasi, C. (2009): "Simulation and estimation of the Meixner distribution", Communication in Statistics - Simulation and Computation, 38, 58-77. 
skewness

$$
\gamma_{1}=S k[X]=\frac{\sin b}{\sqrt{d(\cos b+1)}},
$$

kurtosis

$$
\gamma_{2}=\operatorname{Kur}[X]=3+\frac{3-2\left[\cos \left(\frac{b}{2}\right)\right]^{2}}{d} .
$$

The previous expressions show that $m$ is a location parameter, $a$ is a scale parameter, $b$ is a skewness parameter and $d$ is a kurtosis parameter. Indeed for $b=0$ the Meixner distribution is symmetrical

$$
f(x)=\frac{4^{d}\left|\Gamma\left[d+\frac{i(x-m)}{a}\right]\right|^{2}}{a \pi \Gamma(1+2 d)} .
$$

The coefficient of kurtosis is greater than 3 for any finite $d$ and therefore the Meixner distribution, keeping constant mean and variance, has a higher peak, fatter tails and lower sides than the normal distribution; the positive excess of kurtosis decreases with increasing values of the parameter $d$.

Figure 1 shows the density functions of the Meixner distributions differing in one parameter only.

Figure 1: Probability density functions of the Meixner distribution with different parameters

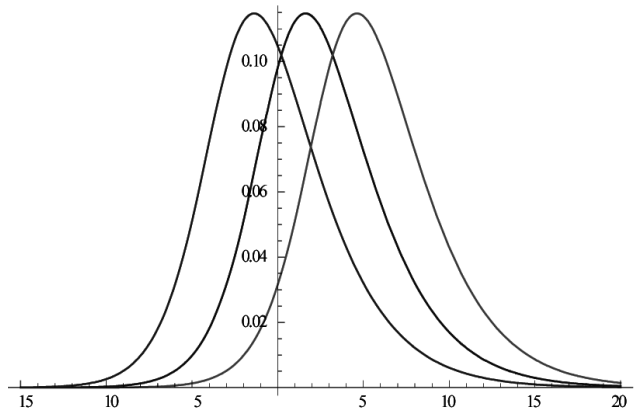

$\mathrm{m}=-3,0,3, \mathrm{~b}=1, \mathrm{~d}=1, \mathrm{a}=5$

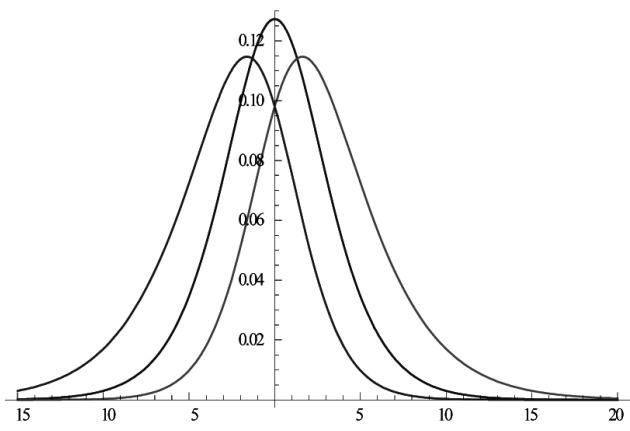

$\mathrm{m}=0, \mathrm{~b}=-1,0,1, \mathrm{~d}=1, \mathrm{a}=5$

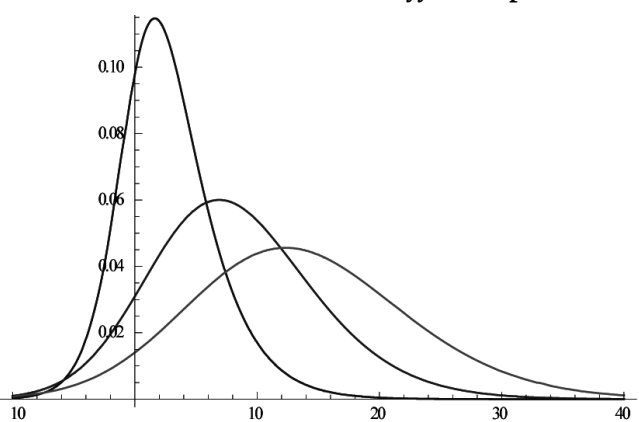

$\mathrm{m}=0, \mathrm{~b}=1, \mathrm{~d}=1,3,5$ e $\mathrm{a}=5$

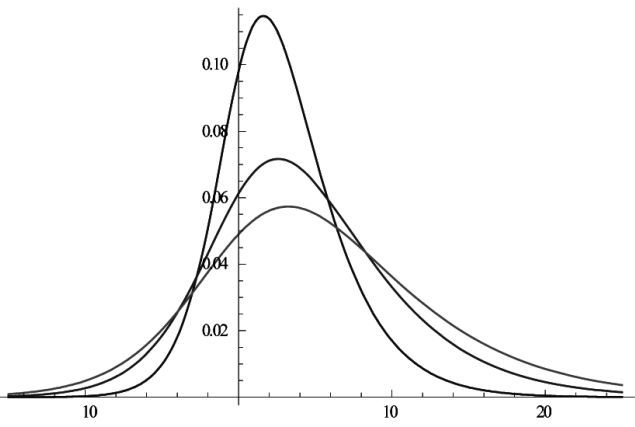

$\mathrm{m}=0, \mathrm{~b}=1, \mathrm{~d}=1, \mathrm{a}=5,8,10$ 
To estimate the parameters of the Meixner distribution we set the expressions of the theoretical moments equal to the values of the empirical moments. In particular we set the expressions of mean $\mu$, variance $\sigma^{2}$, skewness $\gamma_{1}$ and curtosis $\gamma_{2}$ equal to their empirical values, respectively, $\bar{x}, s^{2}, b_{1}$ and $b_{2}$; solving the system of four equations one obtains the parameters estimators:

$$
\begin{aligned}
& \hat{a}=\sqrt{s^{2}\left(2 b_{2}-3 b_{1}^{2}-6\right)}, \\
& \hat{b}=\operatorname{sgn}\left(b_{1}\right) \operatorname{arcocos}\left[\frac{b_{2}-2 b_{1}^{2}-3}{b_{2}-b_{1}^{2}-3}\right], \\
& \hat{d}=\frac{1}{b_{2}-b_{1}^{2}-3}, \\
& \hat{a}=\bar{x}-\hat{a} d \operatorname{g(\frac {\hat {b}}{2})} .
\end{aligned}
$$

The presence of outliers enhances the leptokurtosis of the Meixner distribution fitted to the data and, therefore, the use of suitable devices is necessary to get a good fit? ${ }^{9}$.

The pdf of the Meixner distribution has significant semi heavy tails given by:

$$
\begin{array}{ll}
\text { for } x \rightarrow-\infty, & f(x) \sim C_{-}|x|^{\rho} \exp \left(-\sigma_{-}|x|\right), \\
\text { for } x \rightarrow+\infty, & f(x) \sim C_{+}|x|^{\rho} \exp \left(-\sigma_{+}|x|\right),
\end{array}
$$

where $\rho=2 d-1, \sigma_{-}=\frac{\pi-b}{a}, \sigma_{+}=\frac{\pi+b}{a}, \rho \in \mathbb{R}$, and $C_{-}, C_{+}, \sigma_{-}, \sigma_{+}>0$.

The semiheavyness of the tails of the Meixner distribution allows a good representation of financial data generally characterized by leptokurtosis.

The characteristic function of the Meixner distribution is:

$$
(u)=e^{i m u}\left[\frac{\cos \frac{b}{2}}{\cosh \left(\frac{a u-i b}{2}\right)}\right]^{2 d}
$$

$9 \quad$ Kozlowski,A.(2012): FittingtheMeixnerDistributiontoS\&P500Returns, WolframDemonstrations Project, http://demonstrations.wolfram.com/FittingTheMeixnerDistributionToSP500Returns/. 
which shows that the Meixner distribution is infinitely divisible, in other words the convolution of Meixner identically distributed variables still follows a Meixner distribution.

The exact expressions of other properties of the Meixner distribution such as the mode, the two inflection points, the median, the mean deviation, the mean difference and others are unknown. These values can be computed numerically.

\section{Fitting the Meixner distribution to the USD/EUR exchange rates}

The Black-Scholes model ${ }^{10}$ is a particular Lévy process which assumes that the log-returns

$$
\log \left(\frac{L_{s+t}}{L_{s}}\right)
$$

are normally distributed. The empirical evidence shows that the log-returns distribution of financial data is not normal but it presents a significant leptokurtosis. For this reason Schoutens and Teugels ${ }^{11}$ suggested a more complex Lévy process in which the log-returns follow a Meixner distribution.

Several authors proposed to study the dynamics in exchange rates with the methods used for the dynamics of financial data. Sazuka ${ }^{12}$ and Önalan ${ }^{13}$ studied the changes, respectively, of the USD/JPY rates and of the USD/TRY rates. In this paper we analyzed the dynamics of the changes of the USD/EUR rates referred to recent data. We analyzed a dataset from foreign Exchange market (FOREX), that is a global decentralized market for the trading of currencies. The dataset consisted of the last USD/EUR exchange rates related to time intervals of 5 minutes. Rates were referred to the period of time going from midnight of June 3,2013 to 11.55 pm of January 5, 2015. The total number of the rates was 117,523. We performed a preliminary detrendization process first by subtracting from the original series the series obtained through a 289 -period ( 24 hours) simple moving average and then adding the mean. We derived the log-returns on 24 periods of 5 minutes ( 2 hours) given by:

$$
y_{t}=\log \frac{c_{t}}{c_{t-24}}, \quad \text { for } t=25,49, \ldots, 117,217 \text {, }
$$

$10 \quad$ Black, F., Scholes, M. (1973): “The pricing of options and corporate liabilities”, The Journal of Political economy, 637-654.

11 Schoutens, W., Teugels, J. L. (1998), 1.

12 Sazuka, N. (2007): "On the gap between empirical distribution and exponential distribution of waiting times for price changes in a financial market", Physica A: Statistical Mechanics and its Applications, 376, 500-506.

13 Önalan, Ö. (2011): "Meixner Sureic ile reel efektif doviz kuru'nun modellenmesi", Marmara University I.I.B.F. Dergisi, 30(11), 263-281. 
where $c_{t}$ is the exchange rate at time $t$. The total number of the log-returns was 4,884 . Then we removed ten of the first and the last values of the ordered log-returns series as likely outliers and computed the values of empirical mean, variance, skewness and kurtosis:

$$
\begin{aligned}
& \bar{x}=-0.000000501789, \\
& s^{2}=0.0000011195, \\
& b_{1}=-0.151738, \\
& b_{2}=7.95926 .
\end{aligned}
$$

Figure 2: Histogram of the log-returns of the USD/EUR exchange rates

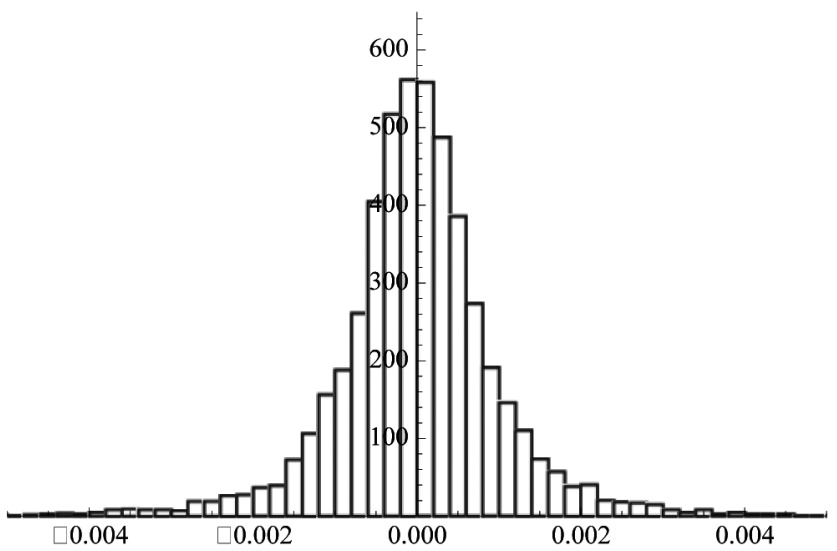

The histogram in Figure 2 represents the series of the log-returns showing its unimodal and bell-shaped distribution and its slight negative skewness. Following the Black-Scholes model we fitted our data with a normal distribution with parameters set equal to the estimates $\bar{x}$ and $\mathrm{s}^{2}$ :

$$
f(x)=\frac{1}{\sqrt{0.0000011195 \cdot 2 \pi}} \mathrm{e}^{-\frac{(x-0.000000501789)^{2}}{2 \cdot 0.0000011195}} .
$$


Figure 3: Histogram and normal density of the log-returns of the USD/EUR exchange rates

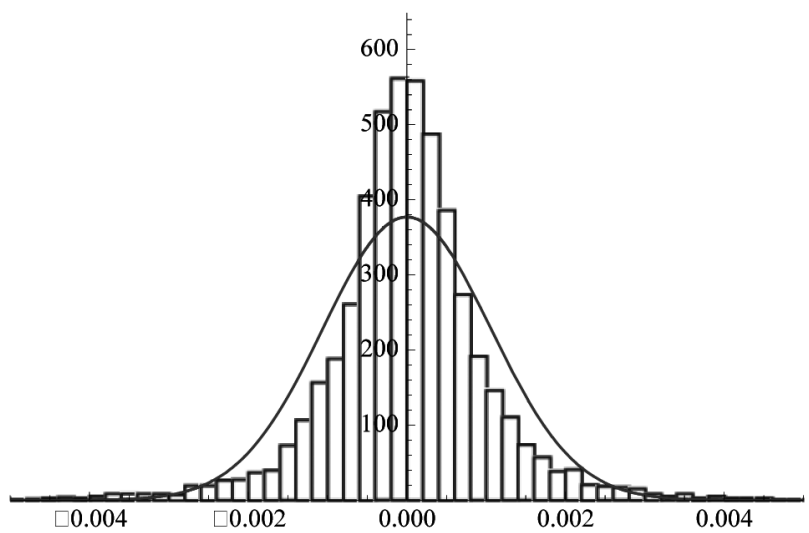

It is evident (Fig. 3) that the normal distribution is not suitable to describe the log-returns of the USD/EUR rates. The histogram shows indeed a slight negative skewness and a significant leptokurtosis with higher peak and tails, as well as sides lower than the normal distribution, typical features of financial data.

Hence, we tried to fit the Meixner distribution to our data set. The point estimators of the mean, variance, skewness and kurtosis of the Meixner distribution, obtained by the method of moments (Sec. 2), had the following values:

$$
\begin{aligned}
& \hat{m}=0.0000330262, \\
& \hat{a}=0.00332061, \\
& \hat{b}=-0.0966228, \\
& \hat{d}=0.202584 .
\end{aligned}
$$

Therefore, the Meixner distribution fitted to the log-returns of the USD/ EUR exchange rates was given by

$$
\begin{aligned}
f(x)= & \frac{\left[2 \cos \frac{-0.0966228}{2}\right]^{2 \cdot 0.202584}}{2 \cdot 0.00332061 \pi \Gamma(2 \cdot 0.202584)} \cdot \\
& \cdot e^{\left[\frac{-0.0966228(x-0.0000330262)}{0.00332061}\right]}\left|\Gamma\left[0.202584+\frac{i(x-0.0000330262)}{0.00332061}\right]\right| .
\end{aligned}
$$

The parameter $b$ is negative because of the slight negative skewness of the distribution. The parameter $d$, that is inversely proportional to the kurtosis, is small and represents, therefore, a high kurtosis. 
Figure 4 shows the empirical histogram and the Meixner distribution fitted to the log-returns of the USD/EUR exchange rates in the observed period. It is clear that the Meixner distribution provides a good fit to our data. To prove the accuracy of the fit we applied first to a quantile-quantile plot (Q-Q plot) and then to the $\chi^{2}$ test.

Figure 4: Histogram and Meixner density of the log-returns of the USD/EUR exchange rates

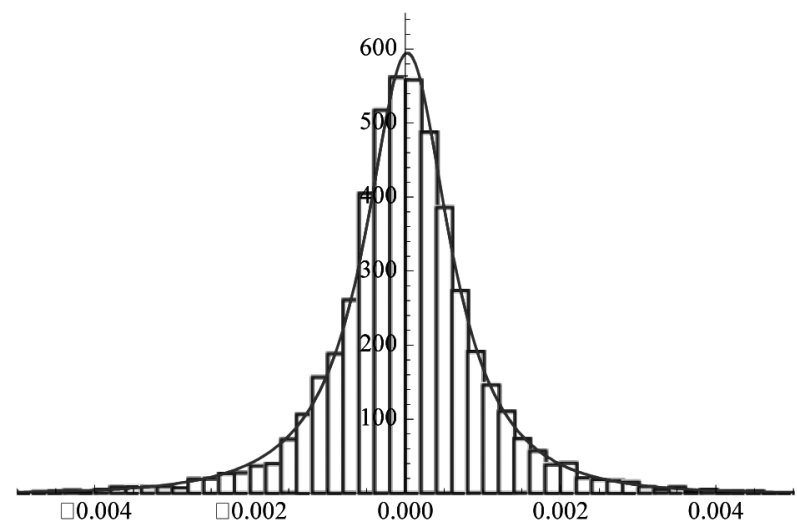

The Q-Q plot is a graphical method that plots the empirical quantiles and the theoretical quantiles of the fitted distribution. If empirical and theoretical quantiles for each frequency are almost equal and therefore the plotted points lie on a straight increasing line, the theoretical distribution provides a good fit to the data.

We considered the 50 -quantiles with levels $0.02,0.04, \ldots, 0.98$. Plotting the $\mathrm{Q}-\mathrm{Q}$ plot of the empirical 50-quantiles and the 50-quantiles of the normal distribution fitted to the data (Fig. 5) it is clear that the points diverge from a straight line in the first and the last ten of the 50-quantiles and therefore it highlights that the normal distribution provides a poor fit of the kurtosis of the log-returns distribution.

The Q-Q plot of the empirical 50-quantiles and the 50-quantiles of the Meixner distribution fitted to the data (Fig. 6) shows that all the points lie on or very near to the straight line and it confirms the better fit of this model to the data. 
Figure 5: Q-Q plot of the empirical and normal quantiles

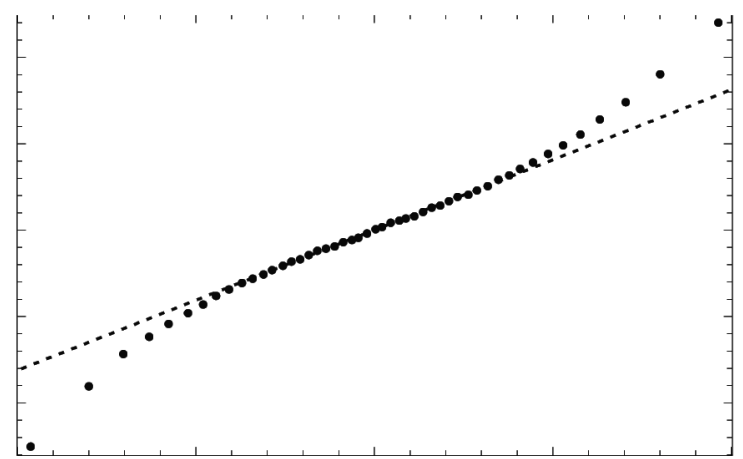

Figure 6: Q-Q plot of the empirical and Meixner quantiles

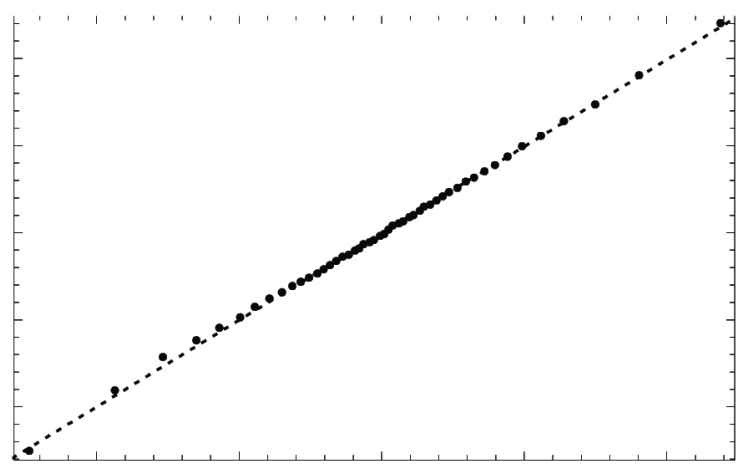

Another tool to test the accuracy of the fit of the Meixner distribution to the empirical data is the $\chi^{2}$ test. We considered 50 classes of equal probability and so we had 50 pairs of empirical $\left(n_{i}\right)$ and theoretical $\left(n_{\mathrm{i}}^{*}\right)$ frequencies. The estimated parameters for the Meixner distribution are 4 and therefore we took 50-4-1=45 degrees of freedom. The value of the $\chi^{2}$ test statistic was

$$
\chi_{45}^{2}=\sum_{i=1}^{50} \frac{\left(n_{i}-n_{i}^{*}\right)^{2}}{n_{i}^{*}}=22.5,
$$

which is lower than the critical value (61.65) at significance level of 0.05 and it leads to the conclusion that there are no significant differences between empirical and theoretical distribution. 


\section{Concluding Remarks}

In this paper we studied the dynamic of the USD/EUR exchange rates. After removing trend to make the series stationary, we obtained the log-returns whose distribution presented a significant leptokurtosis, in contrast with the BlackScholes model which assumes log-returns to be normally distributed. Actually the distribution of the log-returns of the exchange rates differs from the normal distribution because it has a significant leptokurtosis, as it is pointed out in several studies on the dynamic of financial data. We tested the accuracy of the Meixner process which implies that the log-returns follow a Meixner distribution. The fit of the Meixner distribution to the series of the log-returns of each exchange rate and that of two hours before was very satisfactory from the standpoint of the comparison between empirical and theoretical distribution and from the standpoint both of the plotting the empirical quantiles against the theoretical quantiles of the fitted distribution and of the $\chi^{2}$ test evidences.

\section{Acknowledgements}

The author is grateful to Doctor Gaetano Arnaldo Evangelista for cooperation in data acquisition and wishes to express sincere thanks to Professor Giovanni Girone for suggestions on parameter estimation of the Meixner distribution. 


\section{Literature}

- $\quad$ Black, F., Scholes, M. (1973): “The pricing of options and corporate liabilities", The Journal of Political economy, 637-654.

- Grigelionis, B. (1999): "Processes of Meixner Type", Lithuanian Mathematical Journal, 39(1), 33-41.

- Grigelionis, B. (2001): "Generalized Z-distributions and related stochastic processes", Lithuanian Mathematical Journal, 41(3), 239-251.

- Grigoletto, M., Provasi, C. (2009): "Simulation and estimation of the Meixner distribution", Communication in Statistics - Simulation and Computation, 38, 58-77.

- Kozlowski, A. (2012): Fitting the Meixner Distribution to S\&P 500 Returns, Wolfram Demonstrations Project,

- http://demonstrations.wolfram.com/FittingTheMeixnerDistributionToSP500Returns/.

- $\quad$ Mazzola, E., Muliere, P. (2011): "Reviewing alternative characterizations of Meixner process", Probability Surveys, 8, 127-154.

- Önalan, Ö. (2011): "Meixner Sureic ile reel efektif doviz kuru’nun modellenmesi”, Marmara University I.I.B.F. Dergisi, 30(11), 263-281.

- Sazuka, N. (2007): "On the gap between empirical distribution and exponential distribution of waiting times for price changes in a financial market", Physica A: Statistical Mechanics and its Applications, 376, 500-506.

- Schoutens, W., Teugels, J. L. (1998): "Lévy processes, polynomials and martingales", Stochastic Models, 14(1-2), 335-349.

- Schoutens, W. (2001): "Meixner process in Finance", Eurandom Report 2001-002, Eindhoven, 1-21.

- Schoutens, W. (2002): “The Meixner process: Theory and applications in Finance”, Eurandom Report 2001-004, Eindhoven, 1-24.

- Schoutens, W. (2003): Lévy Processes in Finance, New York: John Wiley \& Sons. 
Dr Antonela Nanavekija, vanredni professor

Ekonomski fakultet, Univerzitet LUM „Žan Mone“,

Kasamasima, Bari, Italija

\section{OBRADA FINANSIJSKIH PODATAKA MEISNER PROCESOM}

\section{S a ž e t a k}

Najpoznatiji Blek-Šolov model (Black-Scholes model) zasnovan je na pretpostavci da logaritamski izrazi finansijskih podataka imaju normalan raspored. Međutim, u nekoliko studija u kojima se obrađuju finansijski podaci nije potvrđeno postojanje normalnog rasporeda, jer logaritmi većine finansijskih varijabli pokazuju spljoštenost manju od normalne. Raspored Meisnerovog tipa (Meixner distribution) je beskonačno deljiv i zbog toga, povezan sa Levi procesom (Lévy process), naziva se Meisner procesom (Meixner process). Zahvaljujući njegovoj jednostavnoj i ekstremno fleksibilnoj strukturi, Meisnerovim procesom moguće je na efikasan način predstaviti logaritamski raspored empirijskih podataka finansijskih varijabli. U ovom radu analizirana je dinamika deviznih kurseva SAD dolara i evra. Nakon što je testiranje pokazalo da primenom normalnog rasporeda nije moguće objasniti ovu dinamiku, primenjen je Meisnerov model. Izradom nekoliko statističkih testova, u radu je pokazano da je Meisnerovim rasporedom moguće gotovo perfektno analizirati podatke finansijskih varijabli.

Ključne reči: Levi stohastični proces, Meisnerov raspored, SAD/evro devizni kursevi 